\title{
Joanna Huzarska
}

University of Bialystok, Faculty of Law

\section{Dorota Huzarska}

Medical University of Bialystok, Faculty of Health Sciences

\section{THE OBLIGATION TO TERMINATE \\ A MEDICAL EXPERIMENT - ANALYSIS OF LEGAL REGULATIONS}

\begin{abstract}
The purpose of the present discussion is to present, reflect upon, and evaluate the effective legal regulations concerning the obligation to terminate a medical experiment. The considerations made herein aim at providing an answer to the question whether the aforesaid legal regulations are clear and sufficient. The said analysis is based on the following source: The Act of 5 December 1996 concerning the Professions of General Practitioner and Dental Practitioner. The regulations concerning the obligation to discontinue a medical experiment, both by the will of the participant and on the physician's initiative, are of great importance owing to the fact that they guarantee protection of the patients taking part in the experimental study. The provisions implicitly oblige the physician to monitor the patients' state of health and conduct constant assessment whether or not further carrying on the experiment is expedient and admissible. The legal regulations effective in Poland are explicit and sufficient. Their wording does not raise any considerable reservations. As it appears, the legislature managed to work out appropriate rules so as to minimize the danger zone for the participants of clinical tests and at the same time implement a guarantee that participants' rights shall be respected.
\end{abstract}

Keywords: medical experiment, termination of clinical trial, legal regulations, medical law.

\section{Introduction}

The life and health of every human being are supreme values and as such these assets must be protected by all possible measures. Nowadays, medicine creates new possibilities, thanks to which the average life span has been extended, but on the other hand a number of unknown diseases have occurred. This has resulted in a constant need to search for new and more effective treatment methods, which requires a far better and insightful 
understanding of how the human body functions. Obtaining such knowledge is only possible thanks to carrying out experimental research, which involves a high level of risk due to its innovative nature. There is a hazard of deterioration of the participants' state of health, or in some cases even a threat to their life. Consequently, the pursuit to protect the two assets of vital importance, namely health and life, may unintentionally jeopardize or imperil them. However, without carrying out clinical trials and experiments with human participants, progress in medicine would be impossible. Cessation of conducting medical experiments with humans would consequently hamper development in the field of preventive medicine as well as diagnostic and treatment methods, which would be disadvantageous for the general public.

In the presence of new challenges involved in biomedicine, the legislature's responsibility, in regard to clinical experiments, is to assure the participants' safety and to protect their rights. As it seems, from the perspective of the participant of a clinical trial, the key reassurance that their rights shall be respected is the obligation to obtain the participant's consent (Filar, 2000, p. 159) and securing participants the right to withdraw consent. Deciding about oneself is a fundamental right of every human being. Consent to undergo a medical experiment (as long as it is given voluntarily and consciously) makes the intervention lawful, due to the fact that the participant accepts the risk involved in the clinical trial. Other important factors are the sense of security and reliance on the physician who can decide to cease the experiment if need be. Continuation of the experiment must at all times be justified and safe for the participant.

In compliance with the provisions of the Act concerning the Professions of General Practitioner and Dental Practitioner (hereinafter referred to as the Medical Profession Act) (uniform text Journal of Laws of 2017, item 125), there are three situations obliging the physician to discontinue an experiment that has been commenced:

1. in the event of withdrawal of consent by the participant of the experiment (or any party authorized to do so, i.e. a statutory agent or guardianship court), or

2. if, in the course of a therapeutic experiment, there occurs a serious hazard for the participant's health exceeding the benefits expected for this person, or

3. if, in the course of a research experiment, there occurs an unforeseen threat to the participant's health or life.

The first circumstance might take place in both kinds of experiments: either a therapeutic or a research one. The above follows from the word- 
ing of section 1 of Art. 27 of the Medical Profession Act, which stipulates for a medical experiment in general. The second of the aforesaid situations might happen only in respect of a therapeutic experiment (Art. 27 section 2 of the Medical Profession Act), the third - in the case of a research experiment (Art. 27 section 3 of the Medical Profession Act).

It seems worth emphasizing that while the experiment itself is not defined by the legislature, a general term 'medical experiment' is used. Alongside there are distinguished two types of experiments: therapeutic and research ones.

According to the statutory definition - a therapeutic experiment involves applying new or only partially tried diagnostic methods, medicinal procedures or preventive measures in order to obtain direct benefit for the patient's well-being. Such an experiment may be conducted in the event when medicinal procedures applied so far fail to be effective or if their effectiveness is insufficient (Art. 21 section 3 of Medical Profession Act).

The main purpose of a research experiment, however, is extending medical knowledge. Such an experiment might be conducted both with sick persons as well as with persons who enjoy good health. It is allowed to carry out this type of experiment only if participation does not involve risk or if the risk is limited and does not exceed the desired positive results of the said experiment (Art 21 section 3 of the Medical Profession Act).

The difference between the two types of experiment lies in the main purpose of taking up a clinical trial - whether the experiment is aimed at extending medical knowledge or obtaining direct benefit for a patient's health.

\section{Termination of an experiment as a consequence of withdrawal of the participant's consent}

Pursuant to Art. 27 section 1 of the Medical Profession Act, any person or party authorized to give consent may withdraw such consent at any time in the course of an experiment. In that case, the physician is obliged to terminate the experiment (Nesterowicz, 2016, p. 251; Wnukiewicz-Kozłowska, 2004, p. 122). Let us notice that, prior to the act of giving consent for participation in the study, the participant of the experiment should be informed about their right to withdraw consent (Art. 24 section 1 of Medical Profession Act) (Zielińska, 2008, p. 405). Moreover, in compliance with par. 4 section 3 item 3 letter c of the Regulation concerning detailed rules of appointment, financing and mode of operation of ethics committees (Jour- 
nal of Laws No. 47, item 480; hereinafter as regulation concerning ethics committees), a request for an opinion concerning the planned medical experiment must be accompanied with a copy of the consent form, which ought to contain, among other things, a statement that information regarding the possibility of withdrawal from the experiment at any time has been obtained by the participant. It is a kind of warranty that the obligation to provide information with respect to withdrawing one's consent has been fulfilled.

It follows from Art. 27 section 1 of the Medical Profession Act that:

- Firstly, the right to withdraw one's consent concerns both a therapeutic and a research experiment,

- Secondly, there is a possibility of withdrawing one's consent at any stage of medical experiment,

- Thirdly, in the event of withdrawing one's consent, the physician should terminate the experiment

and

- Finally, consent may be withdrawn only by an authorized person.

To begin with, it needs to be pointed out that the right to withdraw one's consent refers to a therapeutic experiment as well as a research one. There is no exception to that rule. Let it be emphasized that identical treatment of the participants of both kinds of experiments in respect of the right to withdraw consent is absolutely well-founded. There is no reason to resolve otherwise. Both therapeutic and research experiments involve a risk of negative consequences for a participant's health. Indeed, in both events the persons to whom it concerns give their consent to subject themselves to the experiment and therefore they should have equal right to resign from further participation.

Curiously enough, consent withdrawal has an ex nunc effect, which means it does not entail proscription of the experiments conducted so far and activities involved in the previous stages of the clinical trial (Świderska, 2007, p. 312).

As is explicitly stipulated by the legislature, this right may be executed at any stage of the experiment, thus at its beginning phase and at the ultimate one (Ogiegło, 2010, p. 261). In theory such regulation seems unquestionable. In practice, however, some problems may arise. It is a proper question to ask whether the participant of the trial has the right to withdraw from the experiment at the moment when such a decision would result in deterioration of their condition or even cause their instantaneous death. A situation like this was described by P.D. Simmons (Simmons, 1986, p. 6 and next. cited after Rejman, 1991, p. 245). It took place during experiments consisting in implantation of an artificial heart. The first attempts 
led to instantaneous death and the short period when the patients' lives were sustained did not exceed the length of the death throes phase. The author argued that the first patients were in agony and for this reason they demanded that the experiment be terminated, which was tantamount to their death.

As it appears in light of Art. 27 section 1 of the Medical Profession Act, the effectiveness of the said decision does not depend on the fact whether or not their withdrawal from the experiment (termination of the trial) may bring about adverse effects to the health or even life of the person. A conclusion of this sort arises due to the wording of the provision in question. What the legislature sets out here is solely that the physician should terminate the experiment in a case of withdrawing consent. The term "should" is supposed to be understood as "is obliged to do so". There are no additional saving clauses or conditions to the effect that, in exceptional circumstances, the physician would be obliged to continue the experiment regardless of the patient's withdrawing their consent. On the other hand, it seems reasonable to commit the doctor to informing the patient about the fact that termination of the experiment might result in increased hazard to the patient's health or life, so that the participant can make an informed choice. Such regulation indicates respect of the patient's will, who can decide about continuation or termination of the experiment while being fully aware of the risks involved (Kubiak, 2000, p. 51). Needless to say, suppose it might have been anticipated that termination of the trial is likely to cause grave consequences for the patient's health, such information should mandatorily have been given to them prior to their expressing consent and prior to commencing the experiment. This obligation follows directly from Art. 24 section 2 of the Medical Profession Act, which deserves full approval. Under the said provision there is no way to act against the will of the person who wishes to withdraw their consent, and force them to continue their participation in the experiment (Kubiak, 2014, p. 438). Thus, the autonomy and free will of every human being is respected.

In accordance with the foregoing argumentation, should the consent be withdrawn, the experiment must be foreshortened. This naturally follows from the observation that in case of withdrawal of consent, its continued effectuation would be done without consent or even against the will of the participant. Since the authorized person countermands their consent, it amounts to their declaration of indisposition to further take part in the study. This fact needs to be emphasized - if the patient's right to withdraw consent is executed, there is no effective consent on which one may rely. In accordance with binding provisions of law, while such a circumstance occurs, further effectuation of the experiment is no longer legitimate. 
The only situation when an experiment may be conducted without the patient's consent is set out in Art. 25 section 8 of the Medical Profession Act, which provides that in case of emergency and immediate danger to life, obtaining the patient's consent is not necessary. Ergo, one may ponder whether this clause could also apply to a situation when the consequence of consent retraction would be an immediate threat to life. The sequence of events would be as follows: a participant effectively withdraws their consent but the physician does not stop the experiment or stops the trial and instantly resumes it due to the necessity of its continuation, citing authorization under Art. 25 section 8 of the Medical Profession Act. The application of the aforementioned provision then seems inadmissible for at least three reasons. Firstly, the provision refers to commencement of the trial, not its continuation or resumption. Secondly, it applies to the persons incapable of expressing their consent effectively, including its retraction (in the case that is being scrutinized, on the contrary, the participant effectively withdraws their consent while being fully aware). Thirdly, should one allow for the application of the said provision in the analyzed situation, it would represent a circumvention of the provision that guarantees the right to effectively withdraw one's consent, and as such must be considered absolutely inadmissible.

Yet another way of approaching this issue might be to find that the person who resigns from participation in the experiment while realizing that the consequence of withdrawal is death is incapable of expressing an opinion as regards their participation in the study in a mindful manner, thus incapable of expressing consent, and consequently unable to retract it as well. This person's position might be explained as follows - the individual, when deciding to die, acts against the self-preservation instinct, thus must be in a peculiar frame of mind which prevents them from understanding the situation in full. Therefore, such a person should be found incapable of effectively retracting their consent for the experiment, which would authorize the physician to continue the trial. This argumentation seems rather far-fetched, though.

Like it was mentioned before, as a rule, "the doctor should terminate the experiment" if the patient withdraws their consent to participate (Art. 27 section 1 item 2 of the Medical Profession Act). Then, a question ought to be put forward: how is the provision to be interpreted? Shall it be construed as the prescript to terminating the experiment only as regards the person withdrawing their consent, or rather the proscription of carrying on the study in general (i.e. as regards all the participants)? It seems reasonable to assume that the obligation to stop the experiment refers only to 
the participant willing to retract their consent. The above means that the physician is allowed to continue experimental study with other patients' participation (provided that they do not withdraw their consents either). Then, consent retraction affects exclusively the person who requests so. This conclusion is rational, since otherwise one participant could frustrate the whole undertaking. It would mean that this individual enjoys the right to decide about others, which is in opposition to the principle of free will and selfautonomy. Every human being has the right to make autonomous choices about themselves. If other participants in the study choose to quit, they have the right to withdraw their consent. As long as they fail to do so, they are still part of the experiment. In compliance with the above, the obligation to terminate the experiment means cessation of experimental activities only towards the person who retracted their consent. It is allowed to carry on research with other participants and perform procedures that do not require human participation (e.g. analyzing collected samples of research materials, presentation and compilation of data, etc.) (Kubiak, 2000, p. 52). One thing must be pointed out, however, that withdrawing consent by one participant may result in termination of the experiment in full, for instance when the person who quits is the one on whom the whole study relies. Nevertheless, such situations would occur only exceptionally.

Additionally, it needs to be defined who is entitled to withdraw consent. Pursuant to Art. 27 section 1 of the Medical Profession Act it shall be 'a person or other party authorized to give consent'. One may assume that in general every participant of a medical experiment enjoys this right (subject to Art. 25 section 1 item 1). For persons who are incapable of autonomously expressing their consent (persons under age, persons partially or fully incapacitated as well as persons with full capacity to enter into legal transactions but unfit to express their opinion regarding participation in the study with full cognizance), the consent shall be given by statutory representative or guardianship court, ergo - the same entity shall be authorized to withdraw consent. Yet one more situation must be analyzed, when the consent was given jointly (for example by a minor and their statutory representative - Art. 25 section 2 of the Medical Profession Act, or by a fully incapacitated person and their statutory representative - Art. 25 section 4 of the Medical Profession Act). In such an event, it should be deemed that consent withdrawal by one of the parties must result in obligation to bring the experiment to an untimely end (Safjan, 1998, p. 197). According to M. Świderska, if parents retract the consent for a therapeutic experiment with their child whereas the child, acting with cognizance, does not retract their consent, provisions stipulated in Art. 25 section 6 may be applied 
by way of analogy (Świderska, 2007, p. 313). Consequently, parents' objections can be dismissed, and a guardianship court can allow for continuation of the study. Assuredly, it seems a proper thing to endorse such reasoning. Last but not least it ought to be pointed out that, subject to the aforementioned provision, consent may be withdrawn by a person who is currently "authorized to give consent" (that is to say at the moment of consent withdrawal). The above means that there might happen a situation when one entity was authorized to give consent to participate in the study and another is currently competent to retract the consent. To illustrate this, let us consider a minor who was 17 upon the commencement of the experiment but came of age in the course of its duration. Then, consent for participation in the study was given jointly by the minor and their parents, whereas the right to withdraw from the medical trial appertains solely to the minor. The reverse situation cannot be excluded either - for instance a person with full capacity to enter into legal transactions during the course of the study becomes incapacitated and as a result loses the right to autonomously decide about their further participation in the clinical trial. To conclude, it seems worth pointing out the fact that the person's competence to retract their consent must be assessed at the moment of expressing their intent not to take part in the study any further.

Finally, it must be observed that Art. 27 section 1 of the Medical Profession Act, which provides for the possibility of consent withdrawal, does not determine the procedures for doing so. This approach is dissimilar to the provision regarding the manner of giving consent, which expressly regulates that it must be done in a written form. Since the legislator did not regulate the way in which consent may be withdrawn, it appears that the provision stipulated in Art. 60 of the Civil Code ought to be applied (Journal of Laws 2017, item 459). It sets forth, without prejudice to the exceptions provided under the Act, that the intent of the person who enters into legal transactions might be expressed by any kind of action that displays their will in an unambiguous way. Thus, one may draw a conclusion that it is admissible to retract one's consent in any form, even implied. Importantly, such withdrawal must be intelligible and in compliance with the semantic principles known to the addressees (Świderska, 2007, p. 312). To provide an example of behavior tantamount to consent withdrawal, M. Świderska points to a patient's refusal to continue taking medication as part of the experiment or discontinuation of adherence to the rules of the medical trial (Świderska, 2007, p. 312). In such an event, even if the participant does not explicitly declare their withdrawal, the doctor is obliged, at the very least, to ponder over the possibility of termination of the clinical trial. Prior 
to which, the physician should nevertheless make every effort to verify it and ask the patient about their position (Świderska, 2007, p. 312). It appears justified to regulate the issue of the way to cease one's participation in the trail, so as there are no doubts concerning the participant's will and consequently whether or not there exists an obligation to conclude the experiment. Since expressing one's consent must be in written form, then its withdrawal should require an analogous procedure. In exceptional cases, when it is impossible to retract consent in this manner (for example when the participant is too weak to hold a pen), one may stipulate a possibility of retracting the consent in a different manner, for example by way of oral declaration in the presence of two witnesses. On the one hand, such a solution would guarantee protection of the participant reassuring them as to the terms of consent withdrawal procedure so as not to be exposed to misinterpretation of their conduct. On the other hand, until the physician obtains a relevant document, he or she would be obliged to continue the experiment and would not be subject to charges of wrong interpretation of the patient's will / conduct.

\section{The precept of termination of the medical experiment by the physician}

Pursuant to the Medical Profession Act, a physician is obliged to discontinue a clinical experiment at their own initiative in the following situations:

- for therapeutic experiment - if in course of the trial there occurs a risk for the patient's health exceeding the benefits expected for them (Art. 27 section 2 of Medical Profession Act);

- for research experiment - if in course of the trial there occurs unforeseen danger to the patient's health or life (Art. 27 section 3 of Medical Profession Act).

\subsection{The obligation to terminate a therapeutic experiment}

Pursuant to Art. 27 section 2 of the Medical Profession Act, the physician responsible for the experiment is obliged to stop the procedures in case of emergence of a threat to the patient's health which exceeds the potential benefits for the patient.

It follows from the above-mentioned provision that the physician is under unconditional obligation to cease the clinical trial in a specific situation, namely in the event of the occurrence of danger to the patient's health surpassing the prospective benefits for their health. Then, one of the pre- 
requisites of lawfulness of the experiment becomes invalid (the premise of reasonable risk-benefit ratio) (Kędziora, 2009, p. 325). This means that the physician, on their own initiative, is obliged (not entitled) to discontinue a clinical trial. The participant's will, ergo their acceptance or opposition towards the doctor's decision, is of no importance.

What is central here is the circumstance of occurrence of a threat to the patient's health exceeding the expected benefits for this person. One can instantly notice that the legislature expressly indicates that benefits for the individual participant's condition are meant here, not the benefits resulting from the whole undertaking in general, i.e. for the whole group of people suffering from the disease. The said provision is supposed to protect the individual participant of the study, not other persons. From the physician's perspective, the premise to cease the experiment is the emergence of a danger to the patient's health surpassing the anticipated benefits. This means that the very occurrence of danger to health does not constitute a sufficient prerequisite (since such danger is inherently involved in so called novelty risk). What is required by this provision of law is such peril which prevails over the previously expected benefits. Furthermore, the very occurrence of "threat to health" is sufficient, thus health deterioration is not a necessary circumstance. According to the foregoing, the physician cannot wait until health deterioration actually happens should the experiment be carried on further. The doctor must make the decision on cessation of the trial long before, as soon as alarming symptoms occur. Owing to such an approach the patient shall be exposed to a lesser risk of adverse consequences associated with their participation in the study. A situation like this may take place for two reasons:

- if a novel therapy does not bring the desired effects whatsoever, or

- if its effects are hardly noticeable,

the result of which is deterioration of the patient's condition to such extent that failure to achieve the desired result becomes probable (due to poor effectiveness of the therapeutic method which is being tested, or because of the patient's abandonment of conventional therapy).

One should take notice of the fact that the description of the circumstance when the physician is obliged to terminate the experiment in a manner set forth in the provision analyzed above is not precise, and identical facts might in practice be construed in a different way. It is rather judgmental to ascertain the occurrence of a threat to the patient's health surpassing the prospective benefits anticipated for them. Practically, there may happen clear and unambiguous situations raising no doubt whether or not it is necessary to terminate the experiment, but also situations that are 
less clear, ergo balancing on the border of discretionary decision. Nevertheless, it seems difficult to regulate this issue otherwise. Therefore, the sensible judgment of the physician responsible for the experiment must be relied on.

\subsection{The obligation to terminate a research experiment}

Pursuant to Art. 27 section 3 of the Medical Profession Act, the physician responsible for the research experiment is under obligation to terminate it should there occur unforeseen danger to the patient's health or life in the course of its duration.

Like in the case of a therapeutic experiment, it follows from the aforesaid provision that the doctor is unconditionally obliged to break off the experimental procedures in a specific situation, namely upon the occurrence of unforeseen threat to the participant's health or life. That is to say, the onus (not a right) is on the physician to break off a clinical trial. The participant's will, and ipso facto their acceptance or opposition towards the doctor's decision, has no salience.

What is important is the fact of occurrence of an unforeseen threat to health or life. The prerequisite of termination of the experiment is not the very emergence of such threat (since risk is intrinsically involved), but such threat which was not anticipated prior to commencement of the clinical test, and as such was not entailed in the consent expressed by the participant of the experimental study.

Additionally, it is worth pointing out that the very occurrence of "threat" to health or life is sufficient, thus actual deterioration of the patient's condition is not a necessary circumstance. According to the foregoing, the physician cannot wait until health deterioration happens indeed if the experiment is still continued. The doctor must make the decision on cessation of the trial much earlier, as soon as alarming signals occur. Thanks to this the patient shall be exposed to a lesser risk of adverse consequences associated with their participation in the trial.

Let us notice that the description of the circumstance when the physician is obliged to terminate the experiment in a manner set forth in the above analyzed provision is not precise, and in practice identical facts might be construed in a different way. It is rather judgmental to ascertain the occurrence of a threat to the patient's health or life. While one physician may, given identical facts, acknowledge the threat to health, another doctor might not acknowledge it yet. The same refers to ascertaining whether a threat of this kind was taken into consideration before or could be deemed as "unforeseen". Therefore, in practice various situations are likely, both self-evident 
ones, not raising doubts concerning the need to terminate the experiment, as well as less obvious ones, thus on the border of arbitrary opinion.

As it was already asserted herein, the physician is obliged to terminate the experiment if any "unforeseen threat to health or life" occurs. M. Safian argues that "it is easily noticeable how awkward the wording is. Should it be interpreted literally, one would inevitably reach the conclusion that the risk for the patient's health or life, coming into existence in course of conducting the experiment, does not require termination of the trial by the physician provided that it had been anticipated. Needless to say, such a conclusion would be absolutely erroneous. Moreover, the provision is in opposition to the regulation stipulated in Art. 21, which allows only for "minor" risk as regards research experiment. Then, an experiment with anticipated threat to the participant's life would be precluded, which nevertheless seems to be envisaged in Art. 27 section 3" (Safjan, 1998, p. 197). This reasoning must be approved of wholeheartedly. The provision of Art. 27 section 3 of the Medical Profession Act must not be construed literally. One needs to pay attention to its meaning in the context of the protection of a research experiment participant. Pursuant to Art. 21 section 3 of the Medical Profession Act, conducting an experiment is admissible if participation in it does not involve any risk or if the risk is slight. Thus, there is no possibility that any threat to life could be anticipated prior to commencing the trial as such commencement would be permitted. Apparently, the legislature's intention was to safeguard that the research be concluded upon the occurrence of a risk that was not anticipated before (both danger to health, and potential threat to life). It would be reasonable not to provide for an obligation to terminate the experiment in case of "unforeseen threat to life" under Art. 27 section 3 of the Medical Profession Act. There are two reasons for such a solution. First, such a measure would render the said provision more explicit so that it would not raise doubts. Secondly, since the experiment must be discontinued in the event of danger to health, then in case of threat to life such discontinuation seems even more logical. A threat to life is equivalent to a threat to health after all. There is no need to additionally point out the "threat to life".

\section{Conclusions}

While analyzing the provisions of law referring to the physician's obligation to terminate the clinical trial on their own initiative (Art. 27 section 2 and 3 of Medical Profession Act), one must not disregard the fact that in the 
event that the doctor realizes, in the course of a therapeutic experiment, the occurrence of danger to the patient's health exceeding the therapeutic benefits envisaged for the patient, and as for a research experiment, an unforeseen danger to health or life, he or she should also inform the participant of the clinical trial. This is significant due to the fact that such a person, not having a medical education, might be unable to notice that their body is undergoing some changes which may pose a threat to their health or even life. Besides, it is only the head of the study that possesses both adequate research apparatus and professional knowledge and experience, which enable the physician to recognize the danger and, to a certain extent, predict the way the situation may unfold in the near future. Let it be clear that the patient must at all times be fully aware of their situation, even though the physician is obliged to discontinue the experiment on their own initiative. This is substantial also for another reason, namely - when the physician decides not to terminate the trial as yet, the patient will be able to withdraw their consent on their own initiative if they find it appropriate.

Undeniably, the prescript concerning termination of the experiment by the physician which arises from Art. 27 section 2 and 3 of the Medical Profession Act for the participant of the clinical trial in the first place performs a crucial function of enshrinement. Firstly, such a provision implicitly obliges the physician to monitor the patient's state of health, and conduct constant assessment of the progress so as to decide whether or not carrying on the experiment is expedient and admissible (i.e. as regards therapeutic experiment - whether, in the course of the study, there occurred a threat to the patient's health exceeding the potential benefits for the patient, while as regards research experiment - whether there occurred an unforeseen danger to health or life). After all, the patient is unable to ascertain it on their own. Should the doctor happen to fail to comply with this obligation and the situation would demand termination of the trial, the physician would be exposed to charges of nonfeasance of obligation under the said provision of the law. Secondly, in such event the physician must, on their own initiative, discontinue the study. Thirdly, "the purpose of this regulation is to restrain researchers who, aware of adverse effects of their actions, would be inclined to conceal the data until they become self-evident and noticeable for the concerned person" (Kubiak, 2000, p. 51) and thanks to such demeanor be able to continue the whole undertaking at least for some time. It could be particularly dangerous in case of research studies. Last but not least, it gives the physician the legal grounds for discontinuation of the experiment if its further duration causes detriment for the participant who 
wants to continue the study at all costs. Such a situation may take place in the case of therapeutic experiments, for instance when the patient is subjectively convinced that novelty treatment is likely to help them, or the disease is incurable and conventional treatment did not bring about any desired effects, and owing to the above, the sick person does not acknowledge rational explanation of the experiment's failure and the necessity for its termination.

To sum up the above discussion concerning the physician's obligation to discontinue the medical experiment, both on the patient's request (Art. 27 section 1 of Medical Profession Act) and the doctor's own initiative in the occurrence of specific circumstances, i.e.

- if in the course of therapeutic experiment there occurs a risk to the patient's health exceeding the benefits expected for them (Art. 27 section 2 of the Medical Profession Act);

- if in the course of a research experiment there occurs unforeseen danger to the patient's health or life (Art. 27 section 3 of the Medical Profession Act)

one must firmly emphasize the importance of these regulations, as they guarantee protection of the participant of the clinical trial. What is more, their wording, which needs to be stressed once again, does not raise grave doubts.

It may seem then that the legislature managed to work out appropriate rules and regulations so as to minimize the danger zone for the participants of clinical tests and at the same time, in order to guarantee that their rights shall be respected, thanks to which the development of medicine is possible alongside with public acceptance of medical experiments which are conducted.

\section{R E F E R E N C E S}

Filar M. (2000). Lekarskie prawo karne, Kraków.

Kędziora R. (2009). Odpowiedzialność karna lekarza w zwiazku z wykonywaniem czynności medycznych, Warszawa.

Kubiak R. (2000). Zgoda uczestnika eksperymentu - vol I, "Prawo i Medycyna", No. 8.

Kubiak R. (2014). Prawo medyczne, Warszawa.

Nesterowicz M. (2016). Prawo medyczne, Toruń.

Ogiegło L. (2010). Ustawa o zawodach lekarza i lekarza dentysty. Komentarz, Warszawa 2010. 
Regulation of the Minister of Health and Social Welfare of 11 May 1999 concerning detailed rules of appointment, financing and mode of operation of ethics committees (Journal of Laws No. 47, item 480), hereinafter as regulation concerning ethics committees.

Safjan M. (1998). Prawo i medycyna. Ochrona praw jednostki a dylematy współczesnej medycyny, Warszawa.

Simmons P. D. (1986). Ethical Considerrations of Artificial Heart Implantations, "Annals of Clinical and Laboratory Science", 16, 1, p. 6 and next. cited after Rejman G. (1991), Odpowiedzialność karna lekarza, Warszawa.

Świderska M. (2007). Zgoda pacjenta na zabieg medyczny, Toruń.

The Act of 23 April 1964 Civil Code (Journal of Laws 2017, item 459) hereinafter as Civil Code.

The Act of 5 December 1996 concerning the Professions of General Practitioner and Dental Practitioner (uniform text Journal of Laws of 2017, item 125), hereinafter as Medical Profession Act.

Wnukiewicz-Kozłowska A. (2004). Eksperyment medyczny na organizmie ludzkim w prawie międzynarodowym i europejskim, Warszawa.

Zielińska E. (2008). Ustawa o zawodach lekarza i lekarza dentysty. Komentarz, Warszawa. 